\title{
Test water areas for testing technical means of unmanned water transport. The main directions of patenting the results of research and development
}

\author{
Vladimir Karetnikov ${ }^{1}$, Sergey Shakhnov ${ }^{1}$, and Aleksandra Ivanova ${ }^{1, *}$ \\ ${ }^{1}$ Admiral Makarov State University of Maritime and Inland Shipping, 5/7, Dvinskaya Str, 198035, \\ Saint-Petersburg, Russia
}

\begin{abstract}
The test water area is designed for testing, monitoring and navigation of unmanned surface vessel, both in offline mode and in remote control mode. The paper presents the results of the analysis of the thematic search for security documents (applications, patents for inventions and utility models, certificates for computer programs) in the field of testing of technical means of unmanned water transport. There are six groups of patents in this area: test water area; experimental (test) basin; method (technique) of the test (system, complex for tests); test device; test program; remote control (management, monitoring) of the vessel. The distribution of patent documents by type, years, and countries is presented. It was found that almost half of the selected patent documents are applications for inventions, and in 2017-2018, the largest number of protection documents were registered. It is revealed that the Republic of Korea patents the most inventions in this field of research and development, Chinese organizations take the lead in applications for inventions, and Russia mainly registers computer programs. The overall leadership in the development of technical means for the control, management and monitoring, as well as testing of unmanned surface vessels belongs to China. China actively patents its developments in such areas as "test methods" and "remote control, management and monitoring of an unmanned surface vessel". Russia is a leader in the following areas: "programs for test water areas and experimental basins" and "programs for testing unmanned surface vessels". The Republic of Korea is a leader in the field of "devices for testing unmanned surface vessels".
\end{abstract}

\section{Introduction}

The test water area consists of a section of waterways allocated for testing purposes, separated from the main shipping lanes by a special fence, and a complex of technical means of navigation, communication, control and management. It is designed for testing, monitoring, and navigation of unmanned surface vessel (USV), both in offline mode and in remote control mode.

\footnotetext{
*Corresponding author: ageevaalexandra.gumrf@gmail.com
} 
The field of application of the test water area is the testing of both the USV itself and the components of the complex of technical means designed to ensure the navigation of unmanned surface vessels. At the same time, the water area can be used both for testing large-scale models of USV, and their full-size industrial samples.

Since unmanned means of water transport are rapidly developing [1-4], the issue of creating water areas for testing them on waterways is becoming more and more urgent. To date, the 9 test water areas for testing USV are presented in the World and described in open access on official websites and in scientific and technical literature. The leadership in the creation of test water areas for USV belongs to Norway, where three such water areas have already been created: Trondheimsfjorden, Storfjorden and Horten. Another one Tromse will be deployed soon [5].

However, most researchers and developers do not build full-fledged test water areas, but rather test their own unmanned water transport vessels on small sections of waterways located nearby, or in experimental basins [6]. For example, tests were conducted in Suyoung Bay of Busan [7], in Tulu Harbor (near Science Park in Hong Kong SAR) [8], in the Genova Prà harbor [9], in the water area of NUWC Division Keyport [10], on the lake [11] and other inland waterways [12-14].

The object of the study is a test water area for testing technical means of unmanned water transport. Within the framework of this study, a thematic search for security documents (applications, patents for inventions and utility models, certificates for computer programs) was carried out.

The purpose of the patent study is to identify trends in the development of test water areas for unmanned (automatic, autonomous) surface vessels and technical means, information systems and complexes with which they can be equipped, to identify the main patent holders who patent their developments in this field of science, as well as applicants who intend to obtain patents for their developments in the near future.

\section{Materials and Methods}

Since the concept of "technical means of unmanned water transport" refers to both information systems (navigation, identification, monitoring, communication and management) and actually unmanned surface vessels, the patent search was carried out in two directions:

- test water area for unmanned (automatic, autonomous) surface vessels;

- technical means, equipment, information systems and complexes, techniques and methods of testing of unmanned (automatic, autonomous) surface vessels.

In the course of conducting patent research, the main search area for IPC was identified: B63 - vessels and other floating vehicles; equipment for them. Categories and subcategories were also used in the search process:

- B63B 9/02 (methods for the design, construction, repair, reconstruction and operation or characterization of water vehicles using the towing of models in experimental basins);

- B63B 9/08 (definition of vessel characteristics from the point of view of stability and planting);

- B63B 35/00 (Vessels or similar floating devices intended for special purposes);

- B63H 25/42 (vessel control);

- G01M 10/00 (Hydrodynamic tests; devices related to hydro channels or experimental basins for vessels);

- G01M17 (Vehicle testing);

- G05B 17/02 (Regulatory and control electrical systems using models or simulating devices); 
- G05D 1/02 (Systems for controlling or regulating quantities that determine the location in two coordinate systems, the course or position in space of water vehicles);

- G08C 17/02 (Systems for transmitting measured variables, control or similar signals, distinguished by the use of radio communications);

- G08G 3/02 (water transport traffic control systems, collision avoidance devices).

The search was carried out by a combination of two classification categories: G01M10 AND B63, G05B23/00 AND B63, G05D1 AND B63, G08 AND B63, G05B AND B63, G01F AND B63 - that is, the main category (B63) remained unchanged, and the second category in the combination was constantly changing.

According to the above-mentioned IPC classification categories, a substantive search was conducted among Russian, Eurasian, European and international patents, as well as among applications for inventions and utility models filed from 01.01.2012 to 01.11.2019. The search was conducted through electronic databases of research papers and full descriptions of patents for inventions and utility models of the Russian, Eurasian, European and international patent offices, namely, through the database of the Federal Institute of Industrial Property (FIPS) and the database of the European Patent Office, which contains national patents of European countries, Japanese, American, world patents published by the World Intellectual Property Organization (WIPO), as well as patents of other national patent offices.

The method of conducting the search was to study the research papers to the patent documents located in the specified electronic databases, using keywords corresponding to the topic of the study: test area (bed) for unmanned (autonomous, unpiloted) vessel (ship boat); test basin for unmanned (autonomous, unpiloted) vessel (ship boat); test method (device, system, program) for unmanned (autonomous, unpiloted) vessel (ship boat); control of unmanned (autonomous, unpiloted) vessel (ship, boat).

\section{Results}

During the patent search, an array of information was processed in the amount of about 1000 units of patent documentation, namely:

- $\quad$ as a result of the IPC patent search for G01M17 and the keyword "autonomous", 64 patent documents were examined, and for the keyword "unmanned" — 96 patent documents;

- $\quad$ as a result of the IPC patent search for G01M10 AND B63, 275 patent documents were examined;

- as a result of the IPC patent search for G05B AND B63 and the keyword "autonomous", 8 patent documents were examined, and for the keyword "unmanned" - 20 patent documents;

- as a result of the IPC patent search for G05D1 AND B63 and the keyword "autonomous", 106 patent documents were examined, and for the keyword "unmanned" -139 patent documents;

- as a result of the IPC patent search for G08 AND B63 and the keyword "autonomous", 23 patent documents were examined, and for the keyword "unmanned" - 67 patent documents;

- as a result of the IPC patent search for G01F AND B63 and the keyword "unmanned", 2 patent documents were examined;

- $\quad$ as a result of the IPC patent search in the database of computer programs, 179 patent documents were examined. 
To analyze the trends in the development of test water areas, 33 patent documents were selected for testing technical means of unmanned water transport, which can be divided into six groups (Table 1):

- test water area;

- experimental (test) basin;

- method (technique) of the test (system, complex for tests);

- test device;

- program for conducting tests;

- remote control (management, monitoring) of the vessel.

Table 1. Selected patent documents, divided into groups.

\begin{tabular}{|l|l|}
\hline \multicolumn{1}{|c|}{ Group of patents } & \multicolumn{1}{|c|}{ Patents } \\
\hline Test water area & $\begin{array}{l}\text { Patent for invention RU 2639000 } \\
\text { Computer program RU 2019616742 } \\
\text { Computer program RU 2014610624 }\end{array}$ \\
\hline Experimental (test) basin & $\begin{array}{l}\text { Patent for invention RU 2460666 (C2) } \\
\text { Patent for invention KR 101347347 (B1) }\end{array}$ \\
\hline $\begin{array}{l}\text { Method (technique) of the test } \\
\text { (system, complex for tests); }\end{array}$ & $\begin{array}{l}\text { Patent for invention CN 106444776 B } \\
\text { The application for the invention CN 104714418 (A) } \\
\text { The application for the invention CN 106919168 (A) } \\
\text { Patent for invention KR 101772219 (B1) }\end{array}$ \\
\hline Test device & $\begin{array}{l}\text { The application for the invention CN 106314680 (A) } \\
\text { Patent for invention KR 101773605 (B1) } \\
\text { The application for the invention KR 20190082555 (A) }\end{array}$ \\
\hline Program for conducting tests & $\begin{array}{l}\text { Computer program RU 2018612265 } \\
\text { Computer program RU 2018611584 }\end{array}$ \\
Computer program RU 2019611069 \\
\hline $\begin{array}{l}\text { Remote control (management, } \\
\text { monitoring) of the vessel }\end{array}$ & $\begin{array}{l}\text { The application for the invention FI 20175133 (L) } \\
\text { The application for the invention FI 20175127 (L) } \\
\text { The application for the invention CN 107264731 (A) } \\
\text { Patent for invention KR 101880437 (B1) } \\
\text { The application for the invention CN 107402568 (A) } \\
\text { The application for the invention US 2018217588 (A1) } \\
\text { The application for the invention CN 109194385 (A) } \\
\text { Computer program RU 2018663931 } \\
\text { Computer program RU 2015661729 } \\
\text { Computer program RU 2013660213 } \\
\text { Computer program RU 2014615184 } \\
\text { Patent for utility model RU 150949 } \\
\text { The application for the invention US 2017291670 (A1) } \\
\text { The application for the invention CN 105923114 (A) } \\
\text { The application for the invention CN 105116904 (A) } \\
\text { Patent for utility model RU 105 776 } \\
\text { International application for the invention WO 2016191841 } \\
\text { (A1) } \\
\text { The application for the invention CN 108769139 (A) } \\
\text { Patent for utility model CN 208621962 (U) }\end{array}$ \\
\hline
\end{tabular}

Among the selected 33 documents there are seven patents for inventions and two for utility models, fifteen applications for inventions, as well as nine certificates for computer programs (figure 1). In 2012 only one application for the invention/utility model/computer program was filed, in 2013 - two applications, in 2014 - two applications, in 2015 - four applications, in 2016 - two applications, for 2017 - nine applications, in 2018 - eight applications, in 2019 - five applications (figure 2). Over the last three years the total number of filed applications was 22 units, which is $67 \%$ of the total number of applications 
over the last seven years. In 2019, 1.5 times fewer applications were filed than in 2018 and 1.8 times fewer applications than in 2017, which is explained by the fact that the patent search was conducted in September 2019 and during the next three months remaining until the end of the year, the patent database will be replenished. Thus, 2019 does not fully reflect the current state of patent documentation, and for the analysis of the current patent situation, it is advisable to take into account the data from 2012 to 2018. This analysis shows a practically continuously increasing trend in patenting developments in the field of testing unmanned surface vessels.

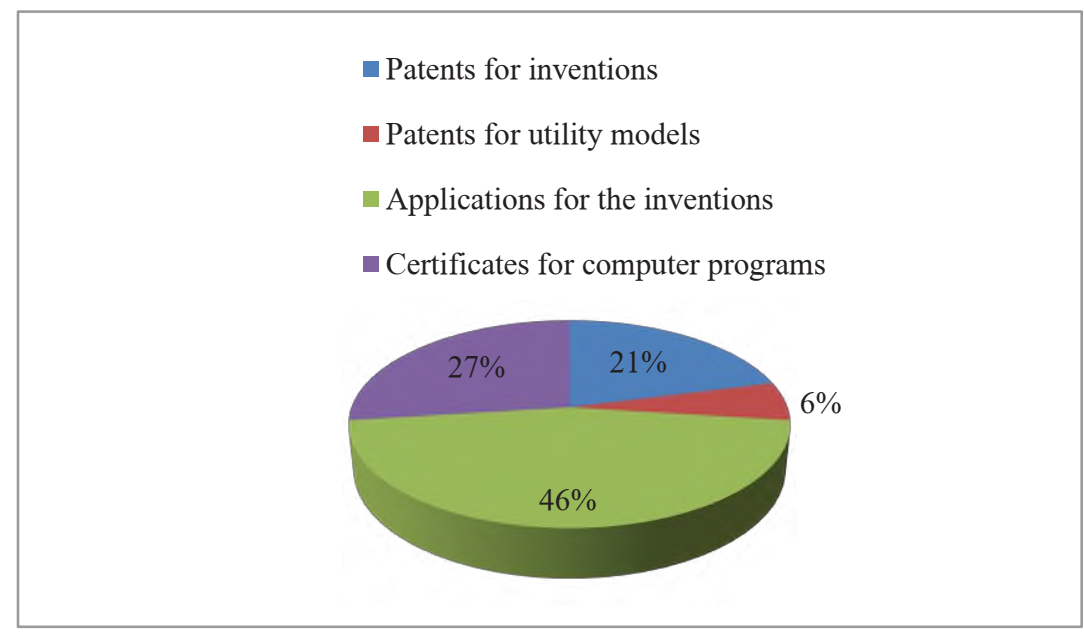

Fig. 1. The composition of the analyzed patent documents.

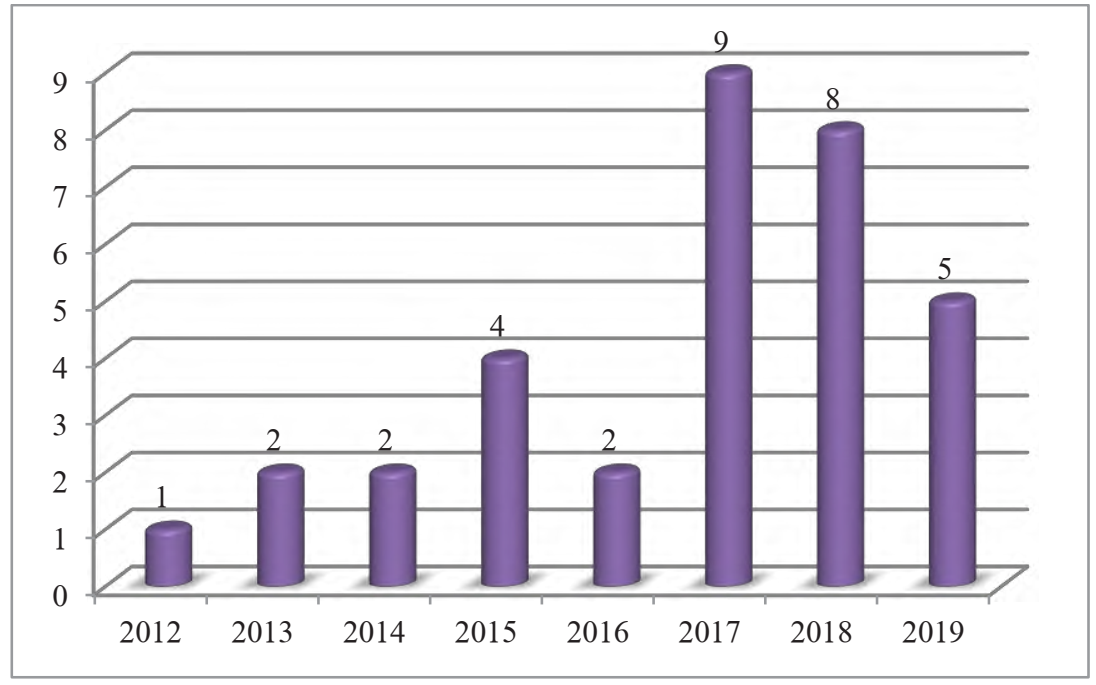

Fig. 2. Number of applications for inventions/utility models/computer programs submitted by year.

\section{Discussion}

During the course of the patent study, patent documents of such countries as Russia, the United States, China, Finland and Korea were selected, as well as one international application (Table 2), the most part of the results of intellectual activity belong to Russian 
and Chinese organizations that have patented twelve and eleven developments, respectively.

Table 2. Quantity and type of patent documents distributed by countries.

\begin{tabular}{|c|c|c|c|c|c|}
\hline \multirow[b]{2}{*}{$\begin{array}{c}\text { Country } \\
\text { of issue }\end{array}$} & \multicolumn{4}{|c|}{ Type of patent document } & \multirow[b]{2}{*}{ Total } \\
\hline & $\begin{array}{l}\text { Patent for } \\
\text { invention }\end{array}$ & $\begin{array}{l}\text { Patent for } \\
\text { utility } \\
\text { model }\end{array}$ & $\begin{array}{c}\text { The } \\
\text { application for } \\
\text { invention }\end{array}$ & $\begin{array}{c}\text { Certificate for computer } \\
\text { program }\end{array}$ & \\
\hline RU & 2 & 1 & - & 9 & 12 \\
\hline $\mathrm{CN}$ & 1 & 1 & 9 & - & 11 \\
\hline KR & 4 & - & 1 & - & 5 \\
\hline US & - & - & 2 & - & 2 \\
\hline FI & - & - & 2 & - & 2 \\
\hline WO & - & - & 1 & - & 1 \\
\hline \multicolumn{5}{|c|}{ Total amount of patent documents for all countries } & 33 \\
\hline
\end{tabular}

According to the FIPS database, the Russian Federation is the right holder of two patents for inventions, one patent for utility model and nine certificates for computer programs. Developers of patens are six state organizations, such as Federal State Autonomous Educational Institution of Higher Professional Education "Southern Federal University" (two certificates for computer programs and one patent for utility model), the Ministry of Industrial Relations and Trade of the Russian Federation (2 patents for inventions), Federal State Unitary Enterprise "Krylov State Research Centre" (two certificates for computer programs), Federal State Autonomous Educational Institution of Higher Professional Education "Saint Petersburg Polytechnic University" (one certificate for computer program) and Federal State Autonomous Scientific Institution "Russian State Scientific Center for Robotics and Technical Cybernetics (RTC)" (one certificate for computer program), and two commercial companies: JSC "Kronstadt" (one certificate for computer program) and JSC "Central Research Institute "Kurs" (two certificates for computer programs). Most of the Russian patents belong to state universities and institutes (9 pcs.), of which the leading position in the number of patents is occupied by the Federal State Autonomous Educational Institution of Higher Professional Education "Southern Federal University".

Chinese patent developments are also divided between state and private organizations, but unlike Russia, most patents are owned by private companies: seven patent documents against four held by universities and institutes: Dalian Maritime University, Jiangsu University of Science and Technology, Beijing Institute of Technology and Systems Engineering Research Institute of CSSC. The private sector is represented by companies such as China Ship Design \& Research Center Co. Ltd. (Beijing), Shanghai Flagship Marine Equipment Co. Ltd., Shanghai Fushi Ship Tech. Co. Ltd., Tianjin Chuangheng Robot Tech Co. Ltd., Autosubsea Vehicles Inc (Shanghai), Zhoushan Yutuo Ocean Eng Tech Co. Ltd., Beijing Nanfeng Kechuang Applic Technology Co. Ltd. and Qingdao Zhongbang Intelligent Tech Co. Ltd.

Each Chinese organization has registered one patent document: China Ship Design \& Research Center Co. Ltd. has patented the invention, Qingdao Zhongbang Intelligent Tech Co. Ltd. has received patent for utility model, and all the others have one filed application for invention. Moreover, the largest part of patent documents belongs to organizations located in the cities Beijing and Shanghai (three documents in each).

The Korean patent documents are submitted by two private companies: Samsung Heavy Industries Co., Ltd (one patent for invention) and KH Systech Co., Ltd (one application for invention) - two and state institutes: Korea Advanced Institute of Science and Technology 
(KAIST) (one patent for invention) and Korea Institute of Ocean Science and Technology (two patents for invention).

The American companies Autonomous Marine Systems, Inc. (Somerville, Massachusetts) and Sea Machines Robotics, Inc. (Boston, Massachusetts) each filed one application for invention. Moreover, both organizations are located in the state of Massachusetts.

The Finnish company Rolls-Royce Oy Ab (Suojantie), which is a partner of the Jaakonmeri test water area project in Finland, has filed two applications for invention, the first of which discloses a remote control center for vessel monitoring (FI 20175133), and the second - a workstation of the coastal operations center (FI20175127). This suggests that these developments will be used in the creation of the Jaakonmeri test water area.

The international application for invention was filed by the Brazilian developer Novaes Decio Nogueira.

From table 2 and figure 3 it follows that the Republic of Korea patents the most inventions, Chinese organizations take the lead in applications for inventions, and Russia mainly registers computer programs.

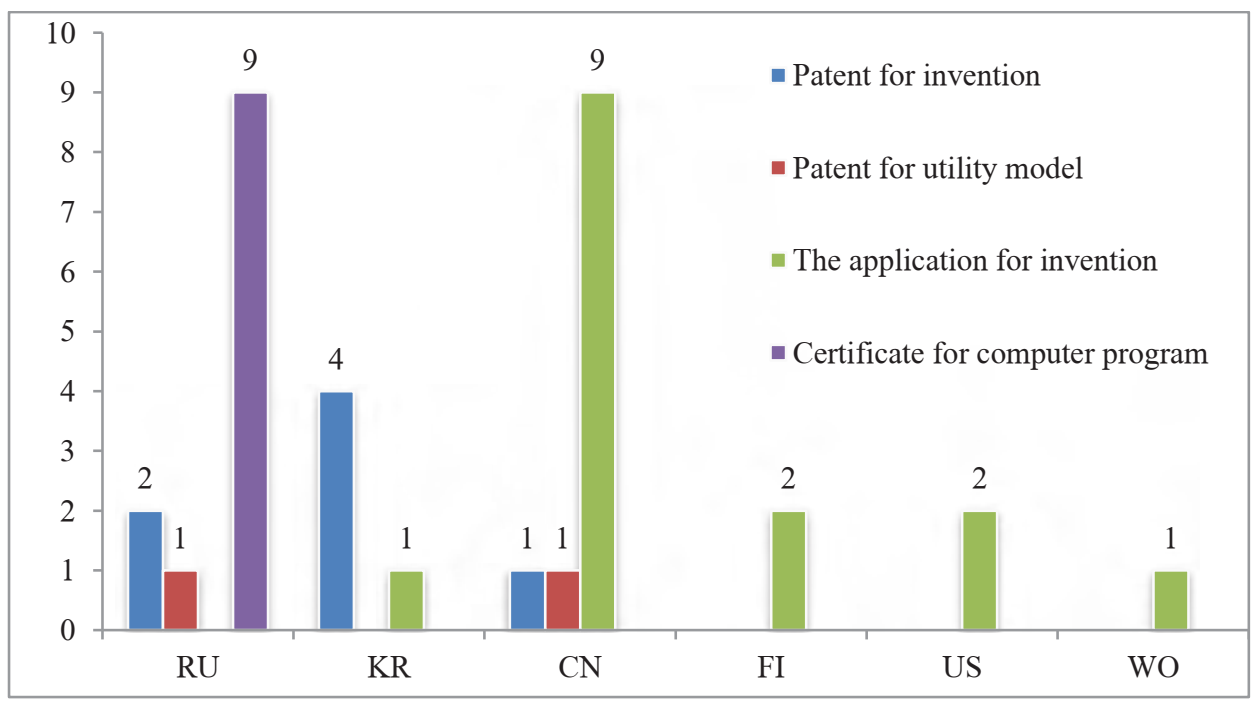

Fig. 3. Distribution of patent documents by countries.

\section{Conclusion}

The analysis of the selected patent documents showed that with the development of unmanned technologies, the market of small vessels with operator control or fully autonomous ones is actively developing, new technologies and devices for their monitoring and control are being introduced. All this makes the task of constructing an efficient and high-tech test water area for testing technical means of unmanned water transport very relevant.

However, the test water areas themselves are not considered by the developers as an object of patent law, only technical means that can be used on test water areas, as well as methods, devices and test programs, are patented.

The analysis of patent documentation showed an almost continuously increasing trend in patenting developments in the field of testing of unmanned surface vessels. Such areas of patenting were found as the method (technique) of the test (system, complex for tests), the 
test device, the test program and the remote control (management, monitoring) of the vessel.

According to the available patent documents, the overall leadership in the development of technical means for the management, control and monitoring, as well as testing of unmanned surface vessels belongs to China, which is represented by the companies: China Ship Design \& Research Center Co. Ltd, Shanghai Flagship Marine Equipment Co. Ltd, Tianjin Chuangheng Robot Tech Co. Ltd, Autosubsea Vehicles Inc., Beijing Nanfeng Kechuang Applic. Technology Co. Ltd. and universities: Dalian Maritime University, Jiangsu University of Science and Technology, Beijing Institute of Technology. China also leads in the sections "test methods" and "remote control, management and monitoring of USV". Moreover, the largest part of patent documents belongs to organizations located in the cities Beijing and Shanghai.

Russia is also represented no less widely, leading in the sections "programs for test water areas and experimental basins" and "programs for testing USV".

The analysis of Russian patent documents showed that the patent holders of technical means for testing, controlling, management and monitoring unmanned surface vessels, along with state organizations: Ministry of Industrial Relations and Trade of the Russian Federation, "Russian State Scientific Center for Robotics and Technical Cybernetics (RTC)", Federal State Unitary Enterprise "Krylov State Research Centre", Federal State Autonomous Educational Institution of Higher Professional Education "Saint Petersburg Polytechnic University" and Federal State Autonomous Educational Institution of Higher Professional Education "Southern Federal University", are commercial companies: JSC "Central Research Institute "Kurs" and JSC "Kronstadt". Moreover, the leader of developments in this area is the Federal State Autonomous Educational Institution of Higher Professional Education "Southern Federal University".

The third largest number of patents in this field is the Republic of Korea, which is the leader in the "testing device" section, represented by companies: Samsung Heavy Industries Co., Ltd, KH Systech Co Ltd, and institutes: Korea Institute of Ocean Science and Technology and Korea Advanced Institute of Science and Technology (KAIST).

The European part of the continent is represented by the Finnish subsidiary of the British multinational corporation Rolls-Royce Holdings plc - Rolls-Royce Oy Ab.

American companies, such as Autonomous Marine Systems, Inc. (Somerville, Massachusetts) and Sea Machines Robotics, Inc. (Boston, Massachusetts), are also actively developing technical means of test water areas for USV.

The study of patent documentation showed that the Republic of Korea patents the most inventions, Chinese organizations take the lead in applications for inventions, and Russia mainly registers computer programs.

It should be noted that although some companies occupy leading positions in the market of unmanned technologies, which is confirmed by their active participation in various exhibitions, conferences, and published works, patent documents of such companies in the field of autonomous navigation cannot be found in the public domain (for example, L3 Harris Technologies), which indicates a high degree of protection of their developments by companies.

\section{References}

1. V. Karetnikov, E. Ol'Khovik, A. Ivanova, A. Butsanets, Energy Management of Municipal Transportation Facilities and Transport, 421-432 (2019)

2. H.H. Cheng, K. Ouyang, Maritime Policy \& Management, 1-15 (2020) DOI: 10.1080/03088839.2020.1768315 
3. X.Y. Zhou, Z.L. Wu, F.W. Wang, Z.J. Liu, Journal of Traffic and Transportation Engineering 19(6), 149-162 (2019) DOI: 10.19818/j.cnki.1671-1637.2019.06.014

4. Z. Liu, Y. Zhang, X. Yu, C. Yuan, Annual Reviews in Control 41, 71-93 (2016) DOI: 10.1016/j.arcontrol.2016.04.018

5. V. Karetnikov, G. Chistyakov, E. Ol'khovik, E3S Web of Conferences 157, 02010 (2020) DOI: 10.1051/e3sconf/202015702010

6. Q. Sun, Z. Qiao, C. Strömbeck, Y. Qu, H. Liu, H. Qian, 13th World Congress on Intelligent Control and Automation (WCICA), 467-473 (2018) DOI: 10.1109/WCICA.2018.8630752

7. N.S. Son, S.Y. Kim, OCEANS 2018 MTS/IEEE Charleston IEEE, 1-5 (2018) DOI: 10.1109/OCEANS.2018.8604803

8. T.L. Lam, H. Qian, Z. Wang, H. Chen, Y. Li, Y. Xu, IEEE International Conference on Robotics and Biomimetics (ROBIO), 1034-1039 (2016) DOI: 10.1109/ROBIO.2016.7866461

9. M. Bibuli, M. Caccia, L. Lapierre, G. Bruzzone, IEEE Robotics \& Automation Magazine 19(3), 92-102 (2012) DOI: 10.1109/MRA.2011.2181784

10. M.W.L. Thein, M. Renken, OCEANS 2018 MTS/IEEE Charleston IEEE, 1-10 (2018) DOI: 10.1109/OCEANS.2018.8604777

11. T. Yang, Y. Guo, Y. Zhou, S. Wei, Joint communication and control for small underactuated USV based on mobile computing technology IEEE 7, 160610-160622 (2019) DOI: 10.1109/ACCESS.2019.2931459

12. J. Zheng, F. Meng, Y. Li, Design and experimental testing of a free-running ship motion control platform IEEE 6, 4690-4696 (2017) DOI: 10.1109/ACCESS.2017.2778180

13. J. Villa, J. Aaltonen, K.T. Koskinen, Third IEEE International Conference on Robotic Computing (IRC), 427-428 (2019) DOI: 10.1109/IRC.2019.00083

14. H. Cao, Z. Guo, Y. Gu, J. Zhou, IEEE 3rd Advanced Information Technology, Electronic and Automation Control Conference (IAEAC), 1574-1577 (2018) DOI: 10.1109/IAEAC.2018.8577260 